\title{
Consenting to HIV-positive organ donation in the USA: legal and ethical considerations in comparison with a South African context
}

This article was published in the following Dove Press journal:

Medicolegal and Bioethics

\author{
Elmi Muller \\ Department of Surgery, University of \\ Cape Town, Groote Schuur Hospital, \\ Cape Town, South Africa
}

\begin{abstract}
Since 2008, 43 HIV positive-to-positive transplants have been performed in Cape Town, South Africa. The ethical decision to utilize HIV-positive donors had been informed by a very unique clinical situation in South Africa. South African transplant recipients are generally young, black patients from low socioeconomic groups where treatment options for their endstage renal disease are limited. Dialysis is not freely available in the country and strict admission criteria exist to access this treatment option. Because South African patients are competing for scarce resources, with many HIV-positive as well as negative patients unable to access dialysis treatment, a transplant with an HIV-positive organ is an acceptable treatment option to many HIVpositive patients in this country. Furthermore, South African HIV-positive patients are generally young and often have low rates of comorbid disease making them ideal transplant candidates. In the USA, HIV-positive patients are generally older and dialysis is freely available to them. Transplantation with HIV-negative organs as well as dialysis are treatment options available to USA-based HIV-positive patients - an important difference to South African patients. Finally, the HIV-positive deceased donors in South Africa are often young trauma victims where HIV is diagnosed at the time of death and the patient is naïve to antiretroviral therapy (ART). In general, South Africa has very low ART resistance rates and a fairly uniform subtype C HIV in the country. This means that using a deceased donor who had been exposed to ART before has a different clinical risk than in the USA, where most donors had been treated with ART and seldom are trauma victims. The author debates in this article how this unique scenario makes use of HIV-positive donors in the USA differently in comparison with South Africa.
\end{abstract}

Keywords: HIV positive, transplantation, deceased donation, HIV positive-to-positive

\section{Introduction}

In 2013, USA adopted the Human Immunodeficiency Virus Organ Policy Equity (HOPE) Act to allow transplantation between HIV-positive donors and recipients in a research study. ${ }^{1}$ Results of South African research using HIV-positive donors for HIVpositive recipients were used to support the formation of this Act. ${ }^{2,3}$ Although South African results were very encouraging, the objective of the HOPE Act was to study the use of HIV-positive donors in the USA where the clinical context was different. Processes in the USA where organ procurement organizations function according to specific guidelines and principles had to be revised to accommodate HIV-positive donors. Furthermore, in the USA HIV-positive living donor transplants are allowed under the HOPE Act, which had never been considered in South Africa. In this article, the author aims to focus on some of the clinical as well as ethical and legal differences that are applicable to the use of HIV-positive donors in South Africa versus USA.
Correspondence: Elmi Muller Department of Surgery, University of Cape Town, Groote Schuur Hospital, Main Road, Observatory 7925, South Africa

Tel +27829 20I III

Email elmi.muller@uct.ac.za
Medicolegal and Bioethics 2018:8 I-10

(c) (i) (3) ( 2018 Muller. This work is published and licensed by Dove Medical Press Limited. The full terms of this license are available at https://www.dovepress.com/terms. you herby you herbby accept the Terms. Non-commercial uses of the work are permitted without any further permission from Dove Medical Press Limited, provided the work is properly attributed. For permission for commercial use of this work, please see paragraphs 4.2 and 5 of our Terms (https.//www.doveperess.com/terms.php. 


\section{The incidence, identity, and prevalence of HIV disease in South Africa versus USA}

For a long time, the political climate in South Africa was one of denial and most politicians denied the impact that HIV had on the country. In Thabo Mbeki's opening address in the 13th AIDS conference in Durban in the year 2000, he pleaded with scientists to respect the politician's point of view. He acknowledged that South Africa has a health crisis of enormous proportions and concluded "we cannot blame everything on a single virus." He emphasized that the world's biggest killer and the greatest cause of ill-health and suffering across the globe (including South Africa) was extreme poverty. ${ }^{4}$

In 2003, after an extensive period in which the South African government denied HIV-positive patients antiretroviral therapy (ART), a program to provide ART was introduced in the country. ${ }^{5}$

The population of South Africa is currently 52.98 million ( $0.7 \%$ of the world's population), but this country accounts for $17 \%$ of the world's HIV-positive population. ${ }^{6}$ In the last decade, several national surveys were carried out to estimate the incidence of HIV in South Africa. ${ }^{7-9}$ Although it has been reported that there is a decline in the incidence of HIV in the younger age groups, the incidence of HIV in the general population of South Africa remains extremely high.

Because the country has steadily made progress in providing ART to patients since 2003, AIDS mortality has decreased and life expectancy has increased. The South African National HIV Survey published in 2012 noted that $12.2 \%$ of the population ( 6.4 million people) was HIV positive in the country. ${ }^{10}$ It is important to note that this was 1.2 million more people than in 2008 when this number was 5.2 million (10.6\% of the population). South Africa has an ongoing problem of a growing population with HIV disease, specifically in the younger age groups. ${ }^{11}$

Overall, South African females have a significantly higher prevalence of HIV than their male counterparts; the prevalence of HIV is the highest in females aged 30-34 and in males aged 35-49. The incidence of HIV among teenager females in South Africa is 8 times higher than males, suggesting that this group is more likely to have sex and probably with older sexual partners (Figure 1).

Other significant findings by the South African National Survey is that HIV has the highest incidence among black South Africans. This is related to the fact that this race group is less likely to live in urban formal areas where the incidence of HIV is lower. It is also related to marital status: black African people are less likely to be married than white, Indian, or Asian people in South Africa. It is reported that HIV is more prevalent in unmarried cohabiting population groups, probably related to higher incidences of sexual transmission. ${ }^{12}$

HIV disease in South Africa is widespread among heterosexual people and the virus in the country is mostly subtype C..$^{13}$

The incidence of HIV in USA is much lower and different subtypes of the virus exist. ${ }^{14}$ Furthermore, the incidence of ART resistance in the USA is much higher. ${ }^{15}$

South Africa has a unique situation in view of the fact that there are low ART resistance rates in the overall population. ${ }^{16-20}$ Because ART was only made available after 2003, all South African patients were started on strict ART protocols involving 3 different drugs. At this stage, it was well known that single drug ART resulted in viral resistance. Therefore, all South African patients received triple ART, resulting in low viral resistance rates throughout the country. Furthermore, the South African government strictly regulated these drugs and protocols for triple therapy were put into place at all HIV clinics, significantly reducing the risk of viral ART resistance.

It is important therefore to note the differences in the HIV-positive population in South Africa versus USA - difference in median age and incidence of comorbid disease in potential HIV-positive donors as well as recipients as well as differences in viral resistance patterns.

\section{Treatment options for patients with end-stage renal failure in South Africa compared to the USA}

South Africa has a well-divided medical system and disparities in health care between the public and private sectors remain a challenge. The public sector currently employs $30 \%$ of the doctors in the country and spends about $\$ 140$ per capita annually. On the other hand, private medical care, that is available to employed South African citizens, provide $\sim \$ 1400$ per capita annually. ${ }^{21,22}$ This disparity in health care continues to widen in South Africa. The public health sector provides health care to $>40$ million people in the country, which constitute $\sim 84 \%$ of the South African national population. Only $16 \%$ of South Africans ( 8 million people) have access to the private medical system, which is served by $70 \%$ of the country's doctors.

In the state sector, dialysis is a scarce commodity and slots for this very expensive treatment are limited. Transplantation is a treatment option for patients with end-stage renal 


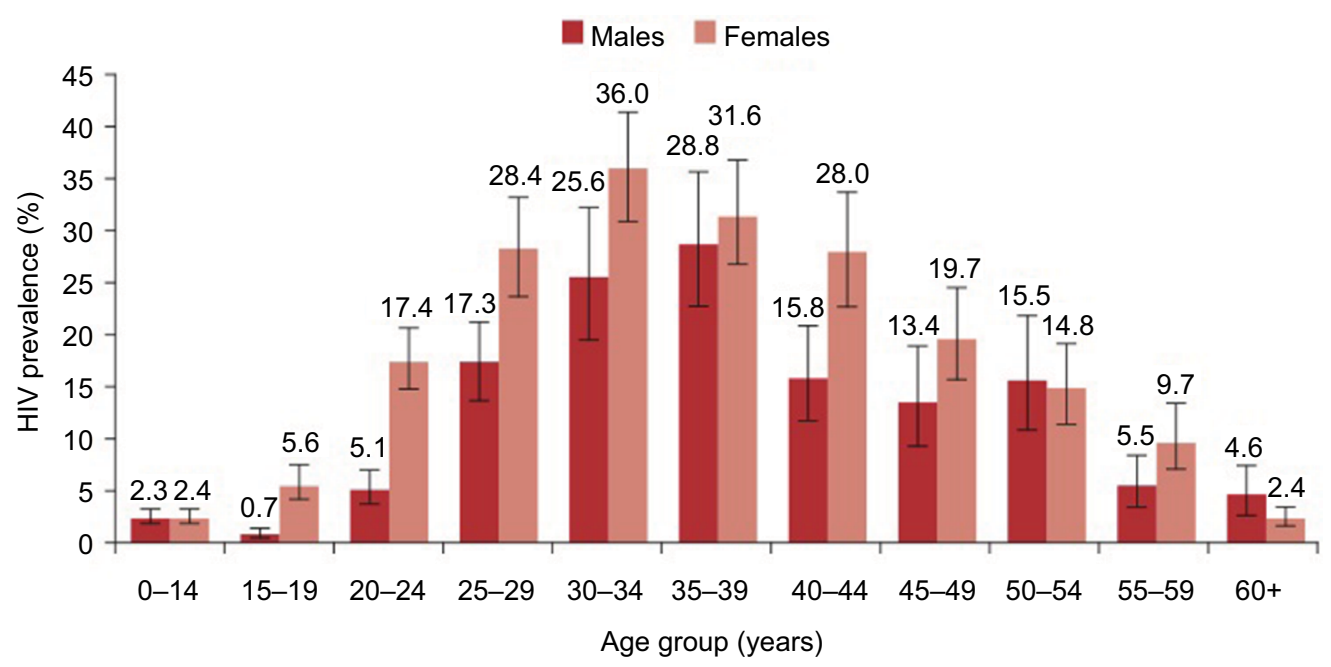

Figure I HIV prevalence by sex and age.

Note: Reprinted with permission from Human Sciences Research Council Press. South African National HIV Prevalence, Incidence and Behaviour Survey, 20I2. HSRC Press, South Africa, 20I4. http://www.hsrc.ac.za/uploads/pageContent/4565/SABSSM\%20IV\%20LEO\%20final.pdf. ${ }^{49}$

Abbreviation: HIV, human immunodeficiency virus.

disease (ESRD) in the state sector. In view of a severe lack of resources, the process of undergoing dialysis and transplantation in the state sector is complicated and extremely competitive.

At Groote Schuur Hospital, patients with ESRD are assessed and presented at a weekly meeting involving physicians, nursing staff, and social workers. Patients are divided into 3 categories according to their medical fitness and socioeconomic circumstances (Supplementary materials). Nephrologists try to accommodate all category 1 patients onto dialysis programs. These patients generally have no medical or social issues, are under the age of 50 years, have a body mass index (BMI) of $<30 \mathrm{~kg} / \mathrm{m}^{2}$, are HIV and hepatitis $B$ surface antigen negative, and South African citizens. Most patients who present at Groote Schuur Hospital do not fall in this category. All patients who develop ESRD secondary to diabetes, hypertension, and HIV disease will automatically be classified as category 2 . However, if a patient falls in category 1 and a dialysis slot is not available, some dialysis bridging therapy in the private sector might be made available to this patient without any direct cost to the patient. So it might happen that a patient gets supported in the private sector until he or she finds a space in the state program if the patient falls in category 1 .

Category 2 patients are patients where there are additional medical conditions present, for instance hypertension with target organ damage, hepatitis $\mathrm{B}$ antigen positive, hepatitis $\mathrm{C}$ positive, diabetes mellitus, and controlled comorbid disease, for instance controlled ischemic heart disease. If a patient has had a previous renal transplant, the patient will automatically be classified as a category 2 patient. Patients with a BMI between 30 and $35 \mathrm{~kg} / \mathrm{m}^{2}$ and between 50 and 60 years will also automatically be classified as category 2 . Any patient with poor home circumstances, for instance lack of storage space, lack of running water, lack of sanitation and electricity, a poor social network and poor support, and who lives far away for the dialysis unit, will be classified as category 2 . The reasoning for this is that these patients are more likely to suffer from opportunistic infections and medical complications related to poor socioeconomic circumstances.

Category 3 patients are generally excluded for dialysis and transplantation. Up to 2010, HIV disease automatically restricted patients to category 3 . This changed at the end of 2010 , and today any patient who has a CD4 count of $>200$ cells $/ \mathrm{mm}^{3}$, is on a stable ART regimen with an undetectable viral load (VL), and who demonstrated good adherence to therapy for at least 6 months can be accepted as a category 2 patient. Category 3 patients also include those older than 60 years of age, patients with a BMI $>35 \mathrm{~kg} / \mathrm{m}^{3}$, hepatitis B e-antigen-positive patients, patients with cirrhosis of the liver, an active malignancy, non-South African citizens, patients with advanced cardiac, liver, or lung disease, or those with an infective process who are not responding to treatment, and patients with a serious mental illness, or those who had used recreational drugs in the past. If a patient has been non-adherent to medical treatment the patient will also be classified as category 3 . A category 3 patient will not be accepted for dialysis.

After the initiation of the successful HIV positive-topositive transplant program in 2008 in Cape Town, access to dialysis in the state sector has become a possibility for HIV-positive patients. However, many patients still present 
very late and only discover that they have HIV once their renal failure gets diagnosed. Many of these patients should be category 2 , but according to the guidelines, a patient who is not yet on ART at the time of the assessment meeting will get turned down for dialysis, as they need $\geq 6$ months of compliance on ART. So the majority of HIV-positive patients who present late will not be able to get access in a state dialysis program. In 2008, when the HIV positive-topositive transplant program at Groote Schuur Hospital started, all HIV-positive patients were classified as category 3 and therefore they did not qualify for dialysis or transplantation in the state sector at all. Today, there is a theoretical possibility for HIV-positive patients who have been on treatment for $>6$ months and with acceptable VL and CD4 counts to access dialysis, but if the patient presents late and is not aware of his/her diagnosis, he/she will be turned down for dialysis even if he/she has no other disease or target organ damage.

The assessment criteria for dialysis in South Africa are based on the principle that patients will only be accepted onto a dialysis program if they are also fit to receive a transplant. The idea is that the dialysis program should naturally feed into the transplant program. Therefore, in South Africa, today, any patient who is not a suitable transplant candidate will automatically be turned down for dialysis. This is not the same in the USA where dialysis is an available treatment modality to all. Before it became clear to medical professionals in South Africa that HIV-positive patients do just as well as HIV-negative patients after transplantation, most nephrologists felt their decision to turn these patients down for dialysis was justified. ${ }^{23,24}$ All decisions were based on the assumption that they will make poor transplant candidates. It is only after the results of the multicenter National Institutes of Health (NIH) study became available that it became widely accepted in South Africa that HIV-positive patients should be considered good transplant candidates..$^{25,26}$ It is interesting to think about the fact that the negative to positive HIV transplant program in the USA opened the door for dialysis and transplantation access to South African patients, and that the HIV positive-to-positive transplant program in South Africa had a major impact on the adoption of the HOPE Act in 2013 back in the USA. ${ }^{27}$

In the USA, all patients can undergo dialysis and there is no policy to exclude any patient from dialysis. This is probably the result of better resources and funding in the health care system and because this treatment option exists for all the patients in the USA, careful consideration should be emphasized on whether the best option for the patient is dialysis, transplantation with an HIV-negative organ versus transplanting with an HIV-positive organ. In South Africa, because dialysis is not freely available and remains difficult to access, the patient does not always have the choice between transplantation and dialysis. However, because dialysis gives such a poor quality of life, it is true that most patients, regardless of whether they have access to dialysis or not, would prefer to undergo a transplant rather than to stay on dialysis - even if this transplant is with a marginal donor.

Using HIV-positive donors in the USA addresses the major shortage of donors in this country, especially in view of the fact that end-stage liver failure is one of the leading causes of death for HIV-positive patients. ${ }^{28}$ As waiting lists remain very long and many USA patients can wait up to 10 years for a deceased donor kidney transplant, many patients will accept an HIV-positive organ instead of waiting on an HIVnegative organ. ${ }^{29}$

\section{The history of transplantation in HIV-positive patients Clinical outcomes using HIV-negative donors in the USA}

Just after the turn of the century, a decision was made in the USA that HIV-positive patients with end-stage kidney and liver disease should be considered for solid organ transplantation with HIV-negative donor organs. It was felt that the risks and benefits associated with organ transplantation in HIV-positive patients should be reconsidered. ${ }^{26}$ At the time of this decision, the reasons for previous concern in the medical community of the USA were first the fear that these patients will take up scarce resources and second that these patients will not do well on immunosuppression. Furthermore, it was felt that these patients might undergo further HIV disease progression and that they should not be put onto immunosuppression for this reason. ${ }^{26}$ With these concerns in mind, a pilot multicenter clinical trial was initiated in June 2001 in the USA. The pilot study involved 275 patients who underwent either kidney or liver transplantation, and enrollment for the study started in 2003. One of the major objections from professionals in the field was the fact that organs from deceased donors were so scarce in the USA. It was felt that it might be ethically unacceptable to allocate organs to a group of patients who might potentially have a poor outcome. ${ }^{24}$

As with every scarce commodity there were 2 options: one was to share these scarce resources on the principle of justice where people will get the organ on the basis of need. The other option was to share these organs on the basis of the 
best clinical outcome. In 2001, before this study was initiated in the USA, HIV-infected patients were not eligible to receive any organs, unless similar good clinical outcomes could be proven. It is in this environment that the NIH multicenter study was set up in the USA to specifically test the outcome of kidney and liver transplantation in HIV-positive patients using HIV-negative recipients. ${ }^{30-32}$

The first results of the USA multicenter study were reported in $2003 .{ }^{33}$ Only patients with a 3 month history of an undetectable plasma HIV-1 RNA level (VL) and a CD4+ T-cell count of $>200$ cells $/ \mu \mathrm{L}$ were considered for enrollment in the study. The authors reported on 14 patients who received transplants. In the group were 10 kidney transplants that were followed up for a mean time of 480 days and 4 liver transplants with a mean follow-up of 380 days. All kidney patients had functioning grafts and 3 of the 4 liver patients were alive with functioning grafts at the time of the publication. The liver patient who died had a rapid recurrence of hepatitis $\mathrm{C}$ infection and died 445 days after the transplant. With these encouraging preliminary data, the study continued and transplantation from HIV-negative donors to HIV-positive recipients continued in the USA.

In 2008, the same group of authors reported results on 11 liver and 18 kidney transplant patients who had been followed up for a median period of 3.4 years. ${ }^{34}$ Follow-up ranged between 2.9 and 4.9 years. The graft survival was encouraging and reported to be the same as the general population in kidney recipients and compatible to older patients in the liver transplant group, based on national data between 1999 and $2004 .^{30}$

\section{Immunosuppression and incidence of rejection}

One of the problems when transplanting HIV-positive patients is the extremely high rejection rates present in this population group. In the NIH multicenter study, very high rejection rates were reported in HIV-positive patients. ${ }^{24,34}$ The 1-year and 3 -year cumulative incidences of graft rejection were $31 \%$ (95\% confidence interval [CI], 24-40) and 41\% (95\% CI, 32-52), respectively. The overall 1-year Scientific Registry of Transplant Recipients rejection rate was estimated to be $12.3 \%$ (95\% CI, 11.9-12.7) and in HIV-positive recipients this was increased to $31 \%(95 \% \mathrm{CI}, 24-40)$ at 1 year and $41 \%(95 \% \mathrm{CI}, 32-52)$ at 3 years. A multivariate proportionalhazards analysis showed that the risk of graft loss was increased among patients treated for rejection (hazard ratio, 2.8; 95\% CI, 1.2-6.6; $P=0.02)$.
These rejection rates are not influenced by the use of an HIV-positive donor and remain the same irrespective of whether an HIV-positive or negative donor is used. Therefore, the inherent risk of rejection should form part of any informed consent discussion with an HIV-positive recipient who considers receiving a transplant, regardless of the donor being HIV positive or negative.

\section{The risk of transplantation with an HIV-positive donor and the risk of a second viral strain}

Because of very high HIV rates in the country, the incidence of HIV among South African brain-dead donors increased between 2004 and 2008. Before 2008, all brain-dead donors who were HIV positive were turned down. However, as more and more HIV-positive patients with ESRD struggled to receive treatment, HIV-positive donors provided an excellent treatment option for these recipients who had limited treatment options in the country. In South Africa, this group of potential donors mostly consists of trauma patients who get referred to the transplant unit as "possible organ donors" according to the critical pathway. ${ }^{35}$ Once the donor is worked up with multiple blood tests and other diagnostic tests, a diagnosis of HIV is sometimes made incidentally. Often, the immediate family or next of kin are unaware that the person had HIV or alternatively the family would not volunteer this information, even if they were aware of the diagnosis. In 2008 , it made sense to try and marry this supply of potential HIV-positive brain-dead organ donors with the group of HIV-positive patients without any treatment options in South Africa. Therefore, an HIV positive-to-positive transplant program was started and this program currently has 43 enrolled patients who have all received kidney transplants from HIV-positive deceased donors. ${ }^{3}$

In 2013, the USA adopted a legislation to make this procedure possible in the USA as well. However, to make sure all potential HIV-positive patients are correctly informed about the additional risks associated with HIV-positive organs, the HOPE Act requires that an independent advocate be appointed for each patient accepting an HIV-positive donor in the USA. ${ }^{36}$ The importance of this lies in the context where USA patients have several treatment options available to them: transplant with an HIV-negative organ, dialysis, and finally the newly added option of transplant with a HIVpositive organ under the HOPE Act.

According to the HOPE Act, it is the responsibility of the independent advocate to inform USA patients that in 
addition to standard donor quality assessment, there are biologic issues specific to HIV that have to be considered when receiving an organ from an HIV-positive donor. There is the risk of HIV super infection (HIV-SI) in the HIV-infected recipient. ${ }^{37,38} \mathrm{HIV}$-SI occurs when an HIV-infected individual is subsequently infected with a new distinctly different strain of HIV. HIV-SI occurs quite commonly with various other modes of transmission, including intravenous drug use and sexual transmission. 39,40

Although potential HIV-infected organ recipients must be on effective ART, and HIV-SI is thought to occur rarely (if at all) in individuals on ART, this risk should be explained to the potential recipient: first, concern due to the potential high viral dose in the transplant and potential transmission of infected cell populations; second, the possibility of introduction of ART-resistant strains; and finally the fact that drug-drug interactions between ART and the immunosuppressive drugs used posttransplantation might result in viral outgrowth or the formation of a new resistant recombinant viral strain.

It is important to know that in considering the risk of using an HIV-positive organ, the true viral inoculum dose in an organ that had been flushed of all its blood is unknown and that it is therefore difficult to quantify the risk. It is unknown how much compartmentalization is present between the viral population in the circulation and in the kidney itself; so, this makes it difficult to predict of how much virus will be transmitted from the donor. The viral inoculum in the transplanted kidneys may be much higher than those associated with sexual exposure or even intravenous drug use as the organs may contain infected peripheral blood mononuclear cells, cell-free plasma virus, infected interstitial lymphocytes, and possibly infected kidney cells and the viral populations found in these compartments may differ. In this context, the principle of non-maleficence is important - first, the patient receiving the HIV-positive organ should not be harmed. However, this risk needs to be carefully weighed up against a long period on a waiting list or death in the case of a patient waiting for a liver transplant.

In the USA, many independent advocates might refer to the results reported in South Africa when using HIV-positive donors. It is important to remember that most South African donors are naïve to ART as they are only diagnosed at the time of brain death. As the South African donors were not exposed to ART before the risk of ART resistance in the recipient is minimal. The occurrence of preexisting ART resistance in either the circulating viral population or memory cell-associated viral reservoir of the donor might compromise protection by ART in the recipient patient. This is an important consideration when weighing up the risk of using an HIV-positive organ in the USA as most donors in the USA are on ART.

\section{The risk of using a marginal organ}

It is currently unknown at what levels the original HIV-infected cellular populations from the receiving patient infiltrate the new donor tissues in the presence of suppressive therapy. It is also unknown whether HIV-infected cellular populations are maintained in the donor tissue in the presence of fully suppressive ART. This might be very important when recurrence of HIV-associated nephropathy (HIVAN) occurs in the donated kidney. The predisposition of a patient to develop HIVAN might be based on clinical, virological, or cellular factors. As it has been reported in the past that the kidney is a viral reservoir, it should be possible to demonstrate the different HIV-1 DNA and mRNA by in situ hybridization and PCR, but this can only be done retrospectively after the transplant as there is no time to do this before the transplant takes place. ${ }^{41-43}$

\section{Important differences between the South African and USA populations when considering HIV positive-to- positive transplantation}

Several important differences need to be considered when comparing options for HIV-positive patients with renal failure in South Africa to those of the USA and other parts of the world. South African patients with HIV are generally very young. This means they have less comorbid diseases, making potential HIV-positive deceased donor organs more suitable with less end organ damage. It also means that South African HIV-positive patients have a reduced medical risk during transplant surgery and follow-up.

South Africa has a very high prevalence of HIV disease and this is particularly true for black African patients. When making decisions around transplantation, organ donation, and accepting an organ from a patient with HIV, cultural differences in this specific population group might influence how the patient reacts to the offer of donating or receiving an HIV-positive organ. Although many black patients in South Africa would decline the opportunity to donate their organs after death because of cultural and religious reasons, it might be that they are more likely to accept an HIV-positive organ because of the limited treatment options available to them. Strict dialysis criteria exist in the state sector hospitals of Western Cape and many patients face a situation where they will not undergo dialysis if their kidneys fail (Supplementary 
materials). Although these criteria do not take race into consideration and all patients depending on the state for treatment face the same dismal medical situation, it is true that many more black patients fall in the lower socioeconomic patient groups, making them more vulnerable and possibly more likely to accept an HIV-positive organ.

Finally, there is a difference in the virological risk a patient takes by accepting an HIV-positive organ in South Africa compared to the risk that a similar transplant recipient in the USA would take. There are very low ART resistance rates in South Africa and there is a fairly uniform subtype $\mathrm{C}$ virus. For this reason, transmitting a donor-derived resistant HIV strain to a transplant recipient in South Africa is less possible than in the USA/elsewhere in the world where resistance rates are much higher. ${ }^{18}$ Furthermore, many patients who are HIV positive in South Africa with HIV disease are not on treatment, because either they are not yet aware of their diagnosis, or they did not fulfill treatment criteria in the country. This will be of particular importance in deceased donors who are often only diagnosed at the time of death and therefore had not been exposed to any ART before.

It might be perceived that a donor with high VL carries a higher risk, but if the reason for this is that the donor was not exposed to any ART before, it actually means that the risk is significantly lower, as the virus is very unlikely to be resistant to any ART in the absence of it being exposed to drugs in the past.

South African patients are therefore faced with a scenario where the virus subtype is fairly uniform (subtype C), where very low resistance rates occur, and where many brain-dead donors are treatment naïve. This makes the decision for a South African patient to accept an HIV-positive kidney somewhat different to the virological scenario that their USA counterparts face.

South African patients have a high incidence of HIVAN, which is responsible for a large proportion of the dialysis population in HIV-positive patients. ${ }^{44,45}$ Because of this long-term risk for renal disease in the living donor and the principle of non-maleficence for all living donors, HIVpositive patients are not eligible to donate their organs while still alive in South Africa. This principle might be different in the USA, where the incidence of HIVAN is much lower, patients get started on ART much earlier, and access to health care is equally available to all citizens. ${ }^{46}$

\section{Informed consent when using HIV- positive donors for HIV-positive recipients}

In order to obtain informed consent for a procedure there is a need to discuss all the different treatment options with the patient. In 2008, when the HIV positive-to-positive program in South Africa started, there were no available treatment options for HIV-positive patients in the state sector hospitals in South Africa. Therefore, offering a patient the treatment option of an HIV-positive deceased donor transplant seemed a reasonable way forward.

However, with policies changing after 2009, HIV-positive patients were now given the option to continue on dialysis, to consent to an HIV-positive kidney, or to remain on the waiting list and wait for an HIV-negative donor. Because of the very long waiting list for HIV-negative patients and the fact that HIV-positive patients would need to compete with HIV-negative patients if they chose to wait for an HIVnegative donor, most HIV-positive patients consented to be on the HIV-positive donor waiting list. It is also true that HIV-positive patients on both the waiting lists were often offered an HIV-positive kidney before they were offered an HIV-negative kidney because of the long waiting time for HIV-negative organs.

During the discussion to obtain consent for the procedure several risks are discussed with the patient. The first risk, namely the risk of rejection, is discussed in great detail with the patient. In the NIH multicenter study, the risk of rejection is estimated to be double that of an HIV-negative patient. ${ }^{24}$ Acute allograft rejection is associated with impaired long-term survival because of the increased risk of developing chronic rejection and it is estimated that the impact on long-term graft survival is to decrease the allograft half-life by $34 \%$. The question of why HIV-positive patients have such high rejection rates remains to be answered. Two major issues are probably associated with this. One is the dysregulated immune system these patients have. And the second is the challenge of managing drug interactions between the ART and immunosuppression. ${ }^{47}$ This risk, however, is not increased by the use of an HIV-positive donor or the second viral strain.

Because of the very high rejection risk all patients receive induction therapy with either antithymocyte globulin (ATG) or thymoglobulin. The effect of the ATG or thymoglobulin induction therapy on the CD4 count is very dramatic and this is discussed with the patient as the second major risk when receiving a transplant. The patient must be prepared that the CD4 count will often drop to $<100$ after the induction therapy. The patient must understand that the CD4 count will recover over the next few years after the transplant. However, because of a very low CD4 count and immunosuppression, the patient is informed about the need to take prophylactic therapy to prevent opportunistic infections. Currently, this 
includes lifelong sulphamethoxazole and trimethoprim to prevent pneumocystis pneumonia, lifelong isoniazid to prevent tuberculosis (TB), as well as oral valgancyclovir for 3-6 months to prevent cytomegalovirus infection. Furthermore, in order to prevent and treat opportunistic as well as general infective episodes, patients need regular monitoring for urinary tract infections, respiratory infection, as well as for serious opportunistic infections like TB and meningitis. For this monitoring, more regular follow-up visits are required and during the informed consent discussion the issue around compliance with clinic visits is discussed in great detail.

Finally, the risk of the second viral strain is discussed with the patient. This can be summarized as recurrence of HIVAN in the kidney or flare-up of the virus in the bloodstream resulting in an increased VL. It could be that the new viral strain is resistant to some of the HIV drugs that the patient is on and that the ART medication needs to be switched. In the South African context, where there are relative low rates of viral resistance, it is unlikely that a transplant will result in a flare-up of a new multidrug-resistant virus or that a new or recombinant virus would not respond to treatment. ${ }^{48}$ This issue is a unique medical problem related to using an HIV-positive donor.

When the study was started, this issue of transferring a second viral strain and what the outcome of that would be, was the main question that had to be answered and patients were informed about the experimental nature of these transplants. However, as the study progressed and no patients had detectable VLs posttransplantation (Abbott Real Time Assay ${ }^{\circledR}$; 6 monthly VLs has not revealed a flare-up in VL in any of the transplanted patients), patients can now be reassured that the second viral strain is unlikely to make a clinical impact. However, sequencing studies looking at subtle changes in the viral strain are still underway.

Patients have to appreciate that the kidney that they receive came from a donor who potentially was untreated with ART, might have a viral reservoir in their kidney as a result of that and this might have an impact on graft survival. The issue of recurrence of HIVAN in the transplanted kidney is currently a major research question in the ongoing study in Cape Town. Although the VL in the patients in Cape Town had remained undetectable, there were 6 patients who developed HIVAN in their transplanted kidneys and in 2 of these patients graft function deteriorated and patients lost their grafts.

Finally, during the conversation around informed consent, the selection process for donors is discussed with the potential recipient. Donors are selected according to the lowest possible clinical risk for a donor-derived disease or illness in the recipient. In other words, donors are chosen to minimize serious harm to the recipient. Therefore, donors with active TB or fungal infection as well as donors with malignancies are turned down as per standard protocol for donor selection in Cape Town.

In the discussion with the patient, it is reasonable to inform them that using an HIV-positive donor is not that different to using any other type of extended criteria donor for a transplant.

\section{Disclosure}

The author reports no conflicts of interest in this work.

\section{References}

1. Human Immunodeficiency Virus Organ Policy Equity (HOPE) Act. Public Law 113-51; 113th Congress; November 21, 2013;127 STAT. 579.

2. Muller E, Kahn D, Mendelson M. Renal transplantation between HIVpositive donors and recipients. N Engl J Med. 2010;362(24):2336-2337.

3. Muller E, Barday Z, Kahn D. HIV-positive-to-HIV-positive kidney transplantation. N Engl J Med. 2015;372(21):2070-2071.

4. Horton R. Mbeki defiant about South African HIV/AIDS strategy. Lancet. 2000;356(9225):225.

5. Simelela NP, Venter WD. A brief history of South Africa's response to AIDS. S Afr Med J. 2014;104(3 Suppl 1):249-251.

6. Abdool Karim SS, Churchyard GJ, Karim QA, Lawn SD. HIV infection and tuberculosis in South Africa: an urgent need to escalate the public health response. Lancet. 2009;374(9693):921-933.

7. Connolly C, Shisana O, Colvin M, Stoker D. Epidemiology of HIV in South Africa - results of a national, community-based survey. $S$ Afr Med J. 2004;94(9):776-781.

8. Shisana O, Hall EJ, Maluleke R, Chauveau J, Schwabe C. HIV/ AIDS prevalence among South African health workers. S Afr Med J. 2004;94(10):846-850.

9. Rehle T, Shisana O, Pillay V, Zuma K, Puren A, Parker W. National HIV incidence measures - new insights into the South African epidemic. $S$ Afr Med J. 2007;97(3):194-199.

10. Shisana O, Rehle T, Simbayi LC, et al. South African National HIV Prevalence, Incidence and Behaviour Survey, 2012. Cape Town: HSRC Press; 2014.

11. Bor J, Fox MP, Rosen S, et al. Treatment eligibility and retention in clinical HIV care: A regression discontinuity study in South Africa. PLoS Med. 2017;14(11):e1002463.

12. Rehle TM, Hallett TB, Shisana O, et al. A decline in new HIV infections in South Africa: estimating HIV incidence from three national HIV surveys in 2002, 2005 and 2008. PLoS One. 2010;5(6):e11094.

13. Johnson LF, Mossong J, Dorrington RE, et al. Life expectancies of South African adults starting antiretroviral treatment: collaborative analysis of cohort studies. PLoS Med. 2013;10(4):e1001418.

14. Boyarsky BJ, Hall EC, Singer AL, Montgomery RA, Gebo KA, Segev DL. Estimating the potential pool of HIV-infected deceased organ donors in the United States. Am J Transplant. 2011;11(6):1209-1217.

15. de Mulder M, York VA, Wiznia AA, et al. HIV-1 drug resistance prevalence, drug susceptibility and variant characterization in the Jacobi Medical Center paediatric cohort, Bronx, NY, USA. HIV Med. 2014;15(3):135-143.

16. Jacobs GB, Laten A, van Rensburg EJ, et al. Phylogenetic diversity and low level antiretroviral resistance mutations in HIV type 1 treatmentnaive patients from Cape Town, South Africa. AIDS Res Hum Retroviruses. 2008;24(7):1009-1012.

17. Parboosing R, Naidoo A, Gordon M, Taylor M, Vella V. Resistance to antiretroviral drugs in newly diagnosed, young treatment-naive HIVpositive pregnant women in the province of KwaZulu-Natal, South Africa. J Med Virol. 2011;83(9):1508-1513. 
18. Nwobegahay JM, Bessong PO, Masebe TM, Mavhandu LG, Iweriebor $\mathrm{BC}$, Selabe G. Prevalence of antiretroviral drug resistance mutations and HIV-I subtypes among newly-diagnosed drug-naive persons visiting a voluntary testing and counselling centre in northeastern South Africa. J Health Popul Nutr. 2011;29(4):303-309.

19. Nwobegahay J, Selabe G, Ndjeka NO, Manhaeve C, Bessong PO. Low prevalence of transmitted genetic drug resistance in a cohort of HIV infected naive patients entering antiretroviral treatment programs at two sites in northern South Africa. J Med Virol. 2012;84(12):1839-1843.

20. Pillay V, Ledwaba J, Hunt G, et al. Antiretroviral drug resistance surveillance among drug-naive HIV-1-infected individuals in Gauteng Province, South Africa in 2002 and 2004. Antivir Ther. 2008;13(Suppl 2): 101-107.

21. Benatar SR, Mayosi BM. Health and health care in South Africa. NEngl J Med. 2015;372(1):96.

22. Coovadia H, Jewkes R, Barron P, Sanders D, McIntyre D. The health and health system of South Africa: historical roots of current public health challenges. Lancet. 2009;374(9692):817-834.

23. Moosa MR, Meyers AM, Gottlich E, Naicker S. An effective approach to chronic kidney disease in South Africa. SAfr Med J. 2016;106(2):156-159.

24. Stock PG, Barin B, Murphy B, et al. Outcomes of kidney transplantation in HIV-infected recipients. N Engl J Med. 2010;363(21):2004-2014.

25. Kuo PC, Stock PG. Transplantation in the HIV+ patient. Am J Transplant. 2001;1(1):13-17.

26. Roland ME, Lo B, Braff J, Stock PG. Key clinical, ethical, and policy issues in the evaluation of the safety and effectiveness of solid organ transplantation in HIV-infected patients. Arch Intern Med. 2003;163(15):1773-1778.

27. Boyarsky BJ, Segev DL. From bench to bill: how a transplant nuance became 1 of only 57 laws passed in 2013. Ann Surg. 2016;263(3):430-433.

28. Scherzer R, Heymsfield SB, Rimland D, et al; Study of Fat Redistribution, Metabolic Change in HIV Infection (FRAM). Association of serum albumin and aspartate transaminase with 5-year all-cause mortality in HIV/hepatitis $\mathrm{C}$ virus coinfection and HIV monoinfection. AIDS 2017;31:71-79.

29. Taha H, Newby K, Das A, Das S. Attitude of patients with HIV infection towards organ transplant between HIV patients. A cross-sectional questionnaire survey. Int J STD AIDS. 2016;27(1):13-18.

30. Stock P, Roland M, Carlson L, et al. Solid organ transplantation in HIVpositive patients. Transplant Proc. 2001;33(7-8):3646-3648.

31. Roland M, Carlson L, Stock P. Solid organ transplantation in HIVinfected individuals. AIDS Clin Care. 2002;14(7):59-63.

32. Roland ME, Stock PG. Review of solid-organ transplantation in HIVinfected patients. Transplantation. 2003;75(4):425-429.

33. Stock PG, Roland ME, Carlson L, et al. Kidney and liver transplantation in human immunodeficiency virus-infected patients: a pilot safety and efficacy study. Transplantation. 2003;76(2):370-375.
34. Roland ME, Barin B, Carlson L, et al. HIV-infected liver and kidney transplant recipients: 1- and 3-year outcomes. Am J Transplant. 2008;8(2):355-365.

35. Dominguez-Gil B, Delmonico FL, Shaheen FA, et al. The critical pathway for deceased donation: reportable uniformity in the approach to deceased donation. Transpl Int. 2011;24(4):373-378.

36. Department of Health and Human Services. Human immunodeficiency virus (HIV) Organ Policy Equity (HOPE) Act safeguards and research criteria for transplantation of organs infected with HIV. Fed Register. 2015;80:34912-34921.

37. Redd AD, Quinn TC, Tobian AA. Frequency and implications of HIV superinfection. Lancet Infect Dis. 2013;13(7):622-628.

38. Redd AD, Collinson-Streng A, Martens C, et al. Identification of HIV superinfection in seroconcordant couples in Rakai, Uganda, by use of nextgeneration deep sequencing. J Clin Microbiol. 2011;49(8):2859-2867.

39. Redd AD, Mullis CE, Serwadda D, et al. The rates of HIV superinfection and primary HIV incidence in a general population in Rakai, Uganda. J Infect Dis. 2012;206(2):267-274.

40. Redd AD, Mullis CE, Wendel SK, et al. Limited HIV-1 superinfection in seroconverters from the CAPRISA 004 microbicide trial. $J$ Clin Microbiol. 2014;52(3):844-848.

41. Canaud G, Dejucq-Rainsford N, Avettand-Fenoel V, et al. The kidney as a reservoir for HIV-1 after renal transplantation. J Am Soc Nephrol. 2014;25(2):407-419.

42. Waters L, Smit E. HIV-1 superinfection. Curr Opin Infect Dis. 2012;25(1):42-50.

43. Streeck H, Li B, Poon AF, et al. Immune-driven recombination and loss of control after HIV superinfection. J Exp Med. 2008;205(8):1789-1796.

44. Wearne N, Okpechi IG. HIV-associated renal disease - an overview. Clin Nephrol. 2016;86(13):41-47.

45. Marras D, Bruggeman LA, Gao F, et al. Replication and compartmentalization of HIV-1 in kidney epithelium of patients with HIV-associated nephropathy. Nat Med. 2002;8(5):522-526.

46. Blumberg EA, Rogers CC; AST Infectious Diseases Community of Practice. Human immunodeficiency virus in solid organ transplantation. Am J Transplant. 2013;13(Suppl 4):169-178.

47. Frassetto L, Thai T, Aggarwal AM, et al. Pharmacokinetic interactions between cyclosporine and protease inhibitors in HIV+ subjects. Drug Metab Pharmacokinet. 2003;18(2):114-120.

48. Fogel J, editor. Undisclosed ARV drug use. HPTN Annual Meeting; 2013.

49. Human Sciences Research Council Press. South African National HIV Prevalence, Incidence and Behaviour Survey, 2012. HSRC Press, South Africa, 2014. Available from: http://www.hsrc.ac.za/uploads/ pageContent/4565/SABSSM\%20IV\%20LEO\%20final.pdf. Accessed December 5, 2017. 


\section{Supplementary materials}

\section{Dialysis assessment criteria at Groote Schuur Hospital in Cape Town, South}

Africa

\section{Category I}

These patients must be accommodated for dialysis:

No category 2 or 3 factors plus all of the following:

- Age $<50$ years

- Body mass index (BMI) $<30 \mathrm{~kg} / \mathrm{m}^{2}$

- Human immunodeficiency virus (HIV) negative

- Hepatitis B surface antigen ( $\mathrm{HBsAg}$ ) negative

- South African citizen.

\section{Category 2}

Medical

- Age 50-60 years

- BMI $30-35 \mathrm{~kg} / \mathrm{m}^{2}$

- Hypertension with target organ damage

- HBsAg or hepatitis $\mathrm{C}$ virus positive with no cirrhosis

- Smoking

- Diabetes mellitus

- HIV positive providing CD4 >200 and undetectable viral load, on antiretroviral therapy demonstrated good adherence and clinical response for $>6$ months

- Late presentation requiring urgent dialysis

- Comorbid disease, for instance stable ischemic heart disease

- Previous kidney transplant.
Social

- Poor home circumstances including lack of storage space, running water, sanitation, and electricity

- Poor social network and support

- No proximity to dialysis unit or capacity to attend the clinic.

\section{Category 3}

Any one excludes the patient:

- Transplantation contraindicated or carries unacceptable risks

- HIV infection other than described in category 2

- Age $>60$ years

- Active substance abuse or dependency

- Morbid obesity (BMI $>35 \mathrm{~kg} / \mathrm{m}^{2}$ )

- Hepatitis B e-antigen positive or cirrhosis

- Diabetes mellitus and age $>50$ years

- Active uncontrolled malignancy with short life expectancy

- Non-South African citizen

- Advanced irreversible progressive vital organ disease such as

- Cardiac, cerebrovascular, or peripheral vascular disease

- Liver disease

- Lung disease

- Unresponsive infections

- Psychological exclusion criteria

- Mental illness resulting in diminished capacity to take responsibility for his/her actions

- Habitual nonadherence with any medical treatment.
Medicolegal and Bioethics

\section{Publish your work in this journal}

Medicolegal and Bioethics is an international, peer-reviewed, open access journal exploring the application of law to medical and drug research and practice and the related ethical and moral considerations. The journal is characterized by the rapid reporting of reviews, case reports, guidelines and consensus statements, original research

\section{Dovepress}

and surveys. The manuscript management system is completely online and includes a very quick and fair peer-review system. Visit http://www.dovepress.com/testimonials.php to read real quotes from published authors. 